\title{
Christine Meyer, Canetti lecteur de Stendhal. Construction d'une écriture autohiographique
}

\section{Michel Arrous}

\section{(2) OpenEdition}

1 Journals

\section{Édition électronique}

URL : https://journals.openedition.org/studifrancesi/46049

DOI : $10.4000 /$ studifrancesi.46049

ISSN : 2427-5856

Éditeur

Rosenberg \& Sellier

\section{Édition imprimée}

Date de publication : 1 octobre 2007

Pagination : 462

ISSN : 0039-2944

\section{Référence électronique}

Michel Arrous, «Christine Meyer, Canetti lecteur de Stendhal. Construction d'une écriture

autohiographique », Studi Francesi [En ligne], 152 (LI | II) | 2007, mis en ligne le 30 novembre 2015, consulté le 24 novembre 2021. URL : http://journals.openedition.org/studifrancesi/46049 ; DOI :

https://doi.org/10.4000/studifrancesi.46049

Ce document a été généré automatiquement le 24 novembre 2021.

\section{(c) $($ ) $\odot$}

Studi Francesi è distribuita con Licenza Creative Commons Attribuzione - Non commerciale - Non opere derivate 4.0 Internazionale. 


\title{
Christine Meyer, Canetti lecteur de Stendhal. Construction d'une écriture autohiographique
}

\author{
Michel Arrous
}

\section{RÉFÉRENCE}

CHRISTINE MEYER, Canetti lecteur de Stendhal. Construction d'une écriture autohiographique, «Études autrichiennes», 2004, n. 12, Centre d'études et de recherches autrichiennes, Publications de l'Université de Rouen, n. 367, pp. 208.

De sa thèse consacrée à Canetti lecteur de Cervantès, Stendhal et Gogol (Paris III, 1997), Christine Meyer a extrait ces pages où l'on voit quel profit Canetti a tiré de la lecture de Stendhal en qui il n'hésita pas à voir son «sauveteur». Le projet comparatiste de Ch. Meyer est plutôt du côté de Philippe Lejeune que de celui des déconstructivistes: examiner les rapports entre l'autobiographie de Canetti et celle de Stendhal, et, particulièrement, étudier le choix des moments clés, la dimension psychologique et politique, les stratégies narratives. Ont été retenus la Vie de Henry Brulard - «Je crois que c'est l'unique autobiographie qui soit absolument vraie», dira Canetti en 1980 - et la trilogie (La Langue sauvée, 1977; Le Flambeau dans l'oreille, 1980; Jeux de regard, 1985) que la critique a souvent reléguée à un rang subalterne, loin d'Auto-da-fé et de Masse et Puissance. L'étude des structures des deux autobiographies se développe selon trois axes principaux: l'élaboration d'une mythologie personnelle, l'invention de la personnalité et la mise en scène du discours autobiographique. On lira avec profit les pages consacrées aux rapports de l'autobiographie avec l'histoire car les deux autobiographes sont des témoins de leur temps qui ont su retracer l'irruption de l'histoire (la Grande guerre, la Révolution) dans leur vie d'enfant. Ch. Meyer a repéré l'importance des anecdotes à partir de deux exemples éloquents: Stendhal prétendant avoir connu le prototype de Mme de Merteuil, et Canetti racontant avoir aperçu Lénine dans un café de Zurich. L'un et l'autre emploient la même technique de restitution de la perspective 
d'un enfant de dix ans. Comme chez Stendhal, on retrouve chez Canetti la mise en relief d'un système de valeurs; tous deux procèdent à une division manichéenne de l'univers familial avec ses modèles et contre-modèles, tous deux organisent leur autobiographie selon un schéma ouvertement partial. C'est d'ailleurs la leçon qu'a tiré Canetti de sa lecture du Brulard, un Canetti dont l'admiration pour Stendhal est fondée sur le fait que ce dernier assume ostensiblement ses sentiments les plus violents, sans jamais chercher à être équitable. À la différence de Rousseau, Stendhal n'hésite pas à avouer ses «crimes», jamais il ne cache son "caractère atroce» ni sa "cruauté»; bien au contraire, il les revendique et fait une apologie soutenue de ses traits de caractère. Même démarche et même attitude chez Canetti dont on comprend qu'il ait pu dire de Stendhal qu'il ne se sentait jamais coupable.

2 La seule différence qu'on puisse relever entre les deux autobiographies - mais elle n'est pas suffisamment argumentée - c'est que Stendhal, à l'instar de Rousseau dont il refuse l'emphase, la fameuse «harpe éolienne», ferait le portrait d'un homme, tandis que Canetti ferait celui d'un écrivain; on pourrait en dire autant de l'assertion selon laquelle la Vie de Henry Brulard serait écrite sur le mode du roman picaresque, tandis que la trilogie le serait sur le mode du roman de formation allemand, le Künstlerroman.

D'une certame manière l'entreprise de Stendhal préfigure l'option canettienne, mais le discours autobiographique de Canetti parait beaucoup plus classique que celui de Stendhal. Chez Canetti, il y a une fermeture du texte et aucun méta-discours, alors que Stendhal emploie l'ironie pour échapper à la complaisance; d'où d'ailleurs l'admiration de Canetti pour Stendhal qui aurait réussi à raconter sa vie, à dire ce qui est le plus personnel sans tomber dans l'étalage du moi, sans faire appel au voyeurisme du lecteur. Pour Ch. Meyer, la Vie de Henry Brulard est une autobiographie critique et l'Histoire d'une vie une autobiographie mythique qui n'aurait jamais vu le jour sans l'exemple provocateur de Stendhal. 